\title{
Users' Perception and Satisfaction with Information Services Provision by Mobile Communication Networks in Zaria, Nigeria
}

\author{
Hadizatu Hassan \\ Librarian II \\ Institute for Agricultural research Library \\ A.B.U Zaria,Nigeria
}

\author{
Ibrahim Umar \\ (UniversityLibrarian \\ Ahmadu Bello University Zaria \\ Nigeria
}

\begin{abstract}
The study was undertaken to determine the users' perception and satisfaction with information services provision by mobile communication networks in Zaria, Nigeria. The study raised three research questions and answers were sought to them, among which are the types of information services provided by mobile communication network to GSM users, as well as the perception of users and their satisfaction with those mobile networks information services. Survey research method was adopted for the study and data was collected from the sample of 1,269 out of the total population of the study of 1534 . The data were analyzed descriptively using frequency tables, percentage, mean, mode, pie chart and histogram. The study revealed that GSM users in Zaria metropolis are provided with awide range of information services The study revealed that users' experience high quality with information services in Etisalat and Airtel network as they rate half (50\%)of their services as good than MTN and GLO. It was also revealed that GSM users are partially satisfied with the overall services of call, S.M.S, Internet, and SIM card service in the entire networks. The study recommends that urgent step should be taken by network providers to reduce the gap by considering users perception in this study rather than from their perception with services quality which will help them to reduce the gap on lower service quality and improve the services quality. Attention should be directed to services with lower satisfaction by setting a target using a set of bench mark of ACSI and N.C.C standard of communication services to serve as a guide for mobile network industries and telecommunication industries to raise the satisfaction level so as to maintain the market share, maintain and generate their users.
\end{abstract}

\section{Keywords}

Communication, Telecommunication, Mobile Communication Networks, Information Services

\section{INTRODUCTION}

It is an established fact that the present era is called information age. It is an age in which information is considered as the raw materials not only to industries, organizations and government but also to individuals. Possession of adequate information by individuals and organization not only to empower them but also bestow on the power no any other organization and individual have. Information is the daily sought and communicated by individual, organization and government. It is also the sequence of symbols that can be interpreted as a message and can be communicated with one another. Many people spend 70 percent of their working hours communicating- writing, reading, speaking and listening. Communication according to Collins (2011) is the essential means of reaching the "bottom of pyramid" which enable individual, organization and government to reduce poverty, improve their standard of living and makes them to extend their skills, attitudes and beliefs to one another.

Taylor (2000) defines communication as the process of giving, receiving or exchanging information, ideas and opinion so that the message is completely understood by both parties. It also involves organizing, selecting and transmitting symbols in an appropriate way to ensure the listener perceives and recreate in his own mind the intended meaning of the communicator.

The development of civilization as known today is largely due to man's activities to exchange information by the natural senses of sight and hearing and by writing words using some forms accepted language and code. Man according to Larry (2001) is constantly searching for means of passing information beyond the normal range of human vision and hearing to the earliest means of passing information over a distance i.e. telecommunicationof the smoke signals used by Africans, American and part of Asia. Others include talking drums, semaphore communication system (optical telegraph) which emerge in Europe in 1792 for transmitting information.

The 20th century telecommunication changes the world immeasurable; while pockets of humankind were once isolated from each other, people now have multiple ways to see and hear what is occurring on the other side of the world in real-time. Today, telecommunications with vast array of technologies that send information over a long distance such as mobile phones, landline, satellite, voice over internet protocol (VOIP) e.t.c. according to Jharwal (2005) enable people around the world to contact one another and to access information instantly and to communicate from remote areas. The simplest form of telecommunication according to declaration on digital divides (2012) took place between two stations; it is common for multiple transmitting and receiving station to exchange data among them. Such an arrangement is called a telecommunication network which comprises of telephone network/mobile communication network (GSM Network); others are computer network, internet, global telex network and aeronautical ACARS network.

\subsection{Statement of Problem}

Mobile communication networks had become the most popular communication industries that help in sustaining the economic growth of a country. In Nigeria, mobile networks ensure the provision, understanding and utilization of 
information services most importantly the quality of informationservices to users to enable them to get a good market share, retain and generate users. The increasing economic importance inspired Parasuraman (1990) to devote attention to this area as he observed the mobile networks ability in improving the service quality with several service quality standards to improve the quality and raise the satisfaction level of users.

Parasuraman (1990) further stated that, despite the several service quality standard to improve the quality and raise the users satisfaction level, users perceived gap when service providers were unable to provide the information services at the desired level, also gap exist between information service delivered and information services received by users and there is also a gap in understanding the basic requirement of users which hindered users from effective communication.

As the researches on users' perception and satisfaction with mobile networks information services were few in Nigeria as that of Adebisi (2012) and Babatunde (2012)., the researcher attempt to conduct this research on GSM users in Zaria metropolis to find out whether the value derived by GSM users is not meeting up to expectations which lead to negative reaction. Also, to fill the void, the researcher adopt SERQUAL model, ACSI and Kano model to identify and reduced such gaps to enable the researcher to yield accurate depictions, recommendations and offer valuable insight for future research.

The following objectives were stated.

1. To determine the types of information services provided by mobile communication networks in Zaria metropolis.

2. To determine how GSM users in Zaria metropolis perceived the various information services of mobile communication networks.

3. To determine the level of satisfaction of GSM users with the information Services of mobile communication networks in Zaria metropolis.

\subsection{Scope of the study}

Zaria metropolis was the geographical scope comprising of Sabongari and Zaria area. The study was limited to four (4) mobile communication networks i.e. MTN, Airtel, Glo, Etisalat. The study does not cover code division multiple access (CDMA) i.e. visa, multilink's and starcom. Short message services (SMS), call services, multimedia services (MMS), call centers, caller ring back tone, mobile internet, SIM card, coverage map, are the information services provided by mobile networks. All these information services were evaluated in making subscribing decision in Zaria metropolis.

\section{LITERATURE REVIEW}

Mobile Communication Networks such as MTN, Airtele.t.c have evolved to take advantage of the digital technology and they are designed to transmit information in a variety of forms e.g. voice, data, video and fax. Mobile communication networks are the telecommunication network where usersequipments are connected to the rest of the network by means of radio link and Users are free to seamlessly roam in the coverage area of the networks. According to ITU (2003) Report, GSM network has been continually enhanced to provide platforms that deliver an increasingly broad range of mobile network services as demand grows where the industries started the plain voice calls. It now has a powerful platform capable of supporting mobile broad band and multimedia services.

\subsection{Nigerian Telecommunication System}

Mobile telecommunication according to Dunnewijk (2007) have become increasingly needed services with high penetration rate in most countries leading to extensive mobile communication usage. The mobile service market is now recognized as the most competitive part of telecommunication sector. The Nigeria mobile telecommunication market is ranked the 10th fastest growing market in the world, which according to the estimate by pyramid research in (2010) report that annual revenue from mobile service represent between 2 per cent and 7per cent of African countries, nominal GDP. In Nigeria this ratio is close to 4 per cent, specifically, it was revealed just recently that the 4 GSM operators in the country MTN, GLO, Airtel, Etisalatremit excess of N264 billion to government annually through company income tax, education tax and government agency task.

Also pyramid research (2010) asserts that Nigeria is recognized as a major market for telecommunication equipment and services on African continent with a population of over 140 million. The telecommunication industries in Nigeria have continued since 1999 to grow exponentially, which has lead to increase access nationwide. The market has been described as one of the fastest growing in telecommunication market, especially between 2001 and 2007. The Nigerian communication commission (NCC) has proven its commitment to promoting regulating environment that is independent, fair, transparent and predictable.

Furthermore, Babatunde, Ajayi and Opaleye (2012) note that Nigeria telecommunication sector was totally deregulated, and since then, the Nigerian Communication Commission (NCC) issued various licenses to private telephone operators in the country. MTN and Airtel-2001, Glo-2003, Etisalat- 2008 and have make the market to be more competitive and easier for users to make choice that meet their actual needs and satisfaction.

\subsection{Perception and Satisfaction Studies}

Perception toward a particular product as opined by Standfort (1981) in support of Babatunde (2012) can only arise if subscribers (users) have actually taste or are involved or subscribed into the usage of such product. For instance, subscribers of MTN, Glo, Airtel and Etisalat have different basic understanding of perception and satisfaction. The perception of MTN subscribers relatively differ when compared to other network providers.

Similarly, Doeskar (2010) explains that quality of service is the main indicator of performance of mobile information services and has recommended that users' perception of the quality of information service should be taken into consideration when determining the overall quality of information services provided by service providers. Since users perception with respect to different mobile information services differs from person to person. Perception need to be measured through survey corresponding to different standards. Doeskar (2010) simply defines service quality as the difference between information service expectation and information service actually received by the users. If the users experience the same information service as they expect then the difference will be zero and one can say the services quality 
is very good. The higher the difference of the above equation the lower will be the service quality

\section{Service quality $=$ Perception - Expectation \\ Information Service Quality}

Information Service quality as define by Deoskar (2010) is the inclusion of all specified features and characteristics as define by product or services and its ability to satisfy the given need as the requirement of users while using it. Parasuraman et al, (1988) pointed out that, in information services, quality is concern with the overall assessment of the services; also Garvin (1986) identified performance, features as the perception of quality base on information service providers' image.

\subsection{Studies on Perception on Quality of Information Services}

These previous researches has emphasize on the quality of information services in which Taylor and Barker (1994) indicate that perceive information service quality and its measurement has become essential focus for the organization in implementing and designing a customer (users)oriented strategy. With customer survey, Cap (2005) found that network quality base on data services and voice services strongly influence users' satisfaction and loyalty with regard to the use of mobile networks.

Parasuraman (1988) develop a list of characteristics that define the information service quality in general they include:

1. Tangible:This is the appearance of physical facilities, equipment, personnel and communication materials.

2. Reliable: This is the ability to perform the promised information service accurately and dependable.

3. Responsiveness: This is the willing to help customers (users) and provide prompt information service to them.

4. Assurance: This is the knowledge of employees and their ability to convey trust and confidence.

5. Empathy: The caring, individualized attention provided to the customers. All these are referred to as (SARVQUAL).

\subsection{Information Service Quality and Users Satisfaction}

According to Backland and Holmquist (2006) that Information Service quality and users satisfaction are two (2) closely related terms, Information service quality can be assess via; is it meeting the standard?, or is it satisfying the users?. Users satisfaction is the perceive degree of fulfillment of expectation and the actual services provided by mobile networks and large investment have been made to increase the level of users satisfaction.

Users satisfaction is totally focus on the information service provided to and perceive by the users: if there is high similarity between perceive and provided information services then the users satisfaction level is very high, that directly lead to high users loyalty for mobile networks or vice versa. There are many benefits of a firm that has a high user satisfaction level, they get a high market share and become compatible of keeping and maintaining their users. Nevertheless, Fornel
(1992) assert that users' satisfaction is a key performance indication within business. Customer satisfaction provides a leading indicator of consumer purchase intention and loyalty. Users' satisfaction data are among the most frequent collected indications of market perception.

Similarly, Doeskar (2010) explains that information service level satisfaction can be measured in terms of customer satisfaction index. A user satisfaction index is a parameter for measuring the user service satisfaction. Measurement of users' satisfaction need to take a number of information services features like coverage, tariff, and attractive value added services scheme.

Other than that, Users' satisfaction is often measured by users' information service, through survey the data can be collected using 5 point likert scale against service parameters. This gives the actual experience against those information services. Overall service quality satisfaction of mobile services is usually obtained through:

$\begin{array}{lll}\text { Completely satisfied } & = & 100 \% \\ \text { Satisfied } & = & 75 \% \\ \text { Neutral } & = & 50 \% \\ \text { Dissatisfied } & = & 25 \% \\ \text { Completely Dissatisfied } & = & 0 \%\end{array}$

If all Users are partially Satisfied (But not completely satisfied) then this satisfaction may have value of $75 \%$

\subsection{Studies on Information Service Quality and Users Satisfaction}

The previous studies such as the ESPI (2006), conduct a study on mobile phone users' satisfaction about quality dimension which was undertaken in Finland and Denmark countries. The important drivers of customer perception of quality emerge product and services in Scandinavian countries and Baltic. The results found that the significant aspect of quality of services include attribute of services, image of the operators and value added services, pricing of services emerge as the most important dimension of quality. In Canada, the consumer satisfaction survey in 2007 was undertaken base on the responses of 6000 mobile users indicated the essential element of quality on mobile network as quality of calls, price, and customer services.

Also, research has been carried out by Souki and Filho (2008) on a study base on 434 users (customers) in Brazil, the study focus on satisfaction of mobile users. The result indicated high rating of customer services, quality of connection and the coverage provided. In Turkey, a study by Ozer and Aydin (2005) has been carried out to determine the National customer satisfaction index of mobile users' base on a sample of 1950 mobile phone subscribers. The dimension that emerged in customer satisfaction included meeting users' expectation, perceive quality in promotional activities and their fulfillment and complain handling.

Competition exist between mobile communication network to retain their customers and to reach maximum number of new customers, because of these competition, users satisfaction plays an important role in the retention of the existing customers in telecommunication industries. This is done by 
offering a wide range of high quality of services that are efficient, cost effective to users.

\subsection{Users (Customer) Retention}

Satisfaction has influence on customer retention and new customer (users) generation. Omotayo and Joachim (2008) pointed out that effective user's information service package has positive chain relationship with customer retention and the result of this will definitely have influence on users' retention and generating new ones. Gran (2006) argue that most banks in the financial services sectors choose not to engage in price but rather make use of service as an effective competition tools. Gront and Dye (1999) opined that the success or failure of generating value is jointly determined by the relationship between service event, the users prior and post perception, and perceive and actual quality of delivered services.

Accordingly, Pura (2005) in support of woodruff (1997) opined that creating superior customer value have a relationship to users satisfaction.

\subsection{Users (Customer) Value}

Wood ruff (1997) opined that the concept of customer value have a relationship to users satisfaction. Nevertheless, Pura (2005) is of the opinion that creating superior customer value is a main goal for firms to obtain competitive advantage and attracted users in currently and future by value creating activities because users buys today regarding to the value or utility for it. Customers segments have different motivation to use, and perceive by customer also differed in value.

Customer value is the idea of perceive benefit and perceive cost, William and Kalchet (2003) In support of Lovelock (2000) argues that the concept of customer value can bring people in different ways of mind, and it is a share of personnel value, belief of right and wrong that is the way to guide people's behavior. In addition, Bettman, Luce and Payne (1998) assert that Customer value perception steer purchase behavior and refer to the value that users perceive, receive or experience by using the services.

Moreover, Zeithmal (1984) has concluded users' perception of value into 4 categories:

\section{Value is low price}

2. Value is whatever a user wants.

3. Value is the quality users get for price he/she pays.
4. Value is what users get for what he/she gives.

Drawing on these four expressions, they captured one general definition that value is a comparison between what users get and what they give and suggesting as general that value is a comparison of the benefit and sacrifice and the users overall assessment of the utility of a service base on the perception of what is receive and what is given.

\subsection{Information Services Provision by Mobile Communication Networks in Nigeria}

Information services are very vital in the telecommunication industries. The growth of mobile telecommunication is responsible for the intense competition between mobile service operators in telecommunication industries. This competition is forcing the operators to adopt effective strategies to satisfy their users (customers). Tung (2004) posits that in order to get more competitive advantage, mobile industries (MTN, Airtel, GLO, Etisalat) have to improve and understand their users' perceptionand also provide the best services like S.M.S, internet, caller tune e.t.c to users in order to increase their level of satisfaction.

\section{METHODOLOGY}

Survey research method was adopted for the study. Out of the 1534 GSM users that constitute the population of the study using2.5 margin of error and 95\% confidence level, $1269(82.72 \%)$ were randomly sampled for the study. One set of questionnaire and semi structured interview were constructed and administered which were retrieved and used for data analysis after three weeks of follow-up. The data collected was analyzed descriptively using frequency count, mean,percentage and mode.

\section{DATA ANALYSIS AND DISCUSSION OF FINDINGS \\ 4.1 Objective 1}

The first research question set to find out the types of information services that are provided to GSM users by mobile communication network in Zaria metropolis. Therefore, to find out this, a visit was undertaken to the branch head quarters of these providers. On inquiry the following information services as indicate in table 1 below are provided to GSM users in Zaria metropolis.

Table 1: Information Services Provided to GSM Users by Network Providers in Zaria Metropolis

\begin{tabular}{|c|c|c|c|c|c|}
\hline \multirow[t]{2}{*}{$\mathrm{S} / \mathrm{N}$} & \multirow[b]{2}{*}{ Information Services } & \multicolumn{4}{|c|}{ Mobile Communication Networks } \\
\hline & & MTN & Airtel & GLO & Etisalat \\
\hline 1 & Call Services & $\sqrt{ }$ & $\sqrt{ }$ & $\sqrt{ }$ & $\sqrt{ }$ \\
\hline 2 & S.M.S & $\sqrt{ }$ & $\sqrt{ }$ & $\sqrt{ }$ & $\sqrt{ }$ \\
\hline 3 & M.M.S & $\sqrt{ }$ & $\sqrt{ }$ & $\sqrt{ }$ & $\sqrt{ }$ \\
\hline 4 & $\begin{array}{l}\text { Mobile } \\
\text { Internet(data) }\end{array}$ & $\sqrt{ }$ & $\sqrt{ }$ & $\sqrt{ }$ & $\sqrt{ }$ \\
\hline 5 & Caller Ring Tone & $\sqrt{ }$ & $\sqrt{ }$ & $\sqrt{ }$ & $\sqrt{ }$ \\
\hline 6 & Coverage Map & $\sqrt{ }$ & $\sqrt{ }$ & $\sqrt{ }$ & $\sqrt{ }$ \\
\hline 7 & SIM Card Information & $\sqrt{ }$ & $\sqrt{ }$ & $\sqrt{ }$ & $\sqrt{ }$ \\
\hline
\end{tabular}




\begin{tabular}{|l|l|l|l|l|l|}
\hline 8 & Call Centers & $\sqrt{ }$ & $\sqrt{ }$ & $\sqrt{ }$ & $\sqrt{ }$ \\
\hline 9 & Location Based Services (LBS) & $\sqrt{ }$ & $\sqrt{ }$ & $\sqrt{ }$ & $\sqrt{ }$ \\
\hline 10 & Promo (Bonus offer) & $\sqrt{ }$ & $\sqrt{ }$ & $\sqrt{ }$ & $\sqrt{ }$ \\
\hline
\end{tabular}

The researcher discovered as reflected in the table above, ten different types of information services provided by mobile communication networks to GSM users in Zaria metropolis. These information services range from call services, S.M.S to location base service and promotion. This implication for this finding confirm the fact that mobile networks provides different services to their users to retain and generate users and to be able to get good market share and protect themselves in the competing business of network industries. This aligned with what Hashed,Salniza and Hamid (2012) observed that delivering information services to users are essential to the well being of any mobile communication industries because it tend to retain their current users, getting the new ones and less users' lost.

\subsection{Objectine 2: Perception of GSM Users on the Information Services provided by $\mathrm{MCN}$ in Zaria Metropolis}

As users' perception arises when users are involved in the usage of services, Deoskar (2010) opined that perception of users should be taken into consideration when determining the quality (main indicator of performance) of information services provided by service providers. This is calculated as the difference between information service expectation and information service received by the users. Therefore in determining the perception of GSM users on the information services provided by MCN in Zaria metropolis, the researcher considered received and expectation of services those have average mean and above score to be the actual mean of acceptability in order to find out how GSM users perceived information services. Each respondent were asked to rate the quality of information services expectation and their experience with the services for the various network providers. They were asked to rate whether the information services quality they are expecting is what they are given using a likert scale of very high, high, no opinion, low and very low in the tables 2 below:

Table: 2 Distribution of GSM users according to expected and received quality of information services by GSM users in Zaria

\begin{tabular}{|c|c|c|c|c|c|c|c|c|c|c|c|c|c|c|c|c|c|}
\hline \multicolumn{2}{|c|}{ Mobile Networks } & \multicolumn{4}{|c|}{ MTN } & \multicolumn{4}{|c|}{ Airtel } & \multicolumn{4}{|c|}{ GLO } & \multicolumn{4}{|c|}{ ETISALAT } \\
\hline \multirow{2}{*}{$\begin{array}{l}\mathrm{S} / \\
\mathrm{N}\end{array}$} & \multirow{2}{*}{$\begin{array}{l}\text { Information } \\
\text { services }\end{array}$} & \multicolumn{2}{|c|}{ Expectation } & \multicolumn{2}{|l|}{ received } & \multicolumn{2}{|c|}{ Expectation } & \multicolumn{2}{|c|}{ received } & \multicolumn{2}{|c|}{ Expectation } & \multicolumn{2}{|l|}{ received } & \multicolumn{2}{|c|}{ Expectation } & \multicolumn{2}{|c|}{ received } \\
\hline & & MEAN & SD & MEAN & SD & MEAN & SD & MEAN & SD & MEAN & SD & MEAN & SD & MEAN & SD & MEAN & SD \\
\hline 1 & Call services & 4.310 & 1.928 & 4.10 & 1.792 & 3.67 & 1.566 & 4.03 & 1.749 & 4.41 & 1.997 & 4.17 & 1.836 & 4.37 & 1.969 & 4.33 & 1.942 \\
\hline 2 & S.M.S & 4.06 & 1.792 & 4.397 & 1.715 & 4.04 & 1.748 & 3.84 & 1.676 & 4.22 & 1.868 & 4.17 & 1.836 & 3.36 & 1.459 & 4.13 & 1.812 \\
\hline 3 & M.M.S & 3.56 & 1.521 & 3.26 & 1.439 & 3.61 & 1.539 & 3.72 & 1.587 & 3.89 & 1.671 & 3.70 & 1.578 & 3.35 & 1.456 & 3.59 & 1.530 \\
\hline 4 & Mobile Internet & 4.22 & 1.868 & 3.79 & 1.690 & 4.08 & 1.780 & 3.77 & 1.608 & 3.98 & 1.721 & 3.68 & 1.569 & 4.16 & 1.829 & 3.90 & 1.676 \\
\hline 5 & Caller ring tone & 3.54 & 1.513 & 3.56 & 1.521 & 3.66 & 1.561 & 3.74 & 1.597 & 3.94 & 1.698 & 3.78 & 1.616 & 3.34 & 1.455 & 3.37 & 1.462 \\
\hline 6 & Coverage map & 3.34 & 1.455 & 3.13 & 1.420 & 3.39 & 1.466 & 3.61 & 1.539 & 3.91 & 1.682 & 3.34 & 1.455 & 3.39 & 1.466 & 3.13 & 1.420 \\
\hline 7 & SIM card & 4.13 & 1.812 & 3.64 & 1.552 & 4.01 & 1.738 & 3.75 & 1.600 & 4.07 & 1.473 & 3.91 & 1.682 & 3.85 & 1.649 & 3.94 & 1.689 \\
\hline 8 & Call center & 4.06 & 1.792 & 3.45 & 1.483 & 3.89 & 1.671 & 3.59 & 1.530 & 4.03 & 1.749 & 3.71 & 1.581 & 3.02 & 1.414 & 3.41 & 1.473 \\
\hline 9 & $\begin{array}{l}\text { Location base } \\
\text { services }\end{array}$ & 3.24 & 1.435 & 3.02 & 1.414 & 3.83 & 1.640 & 3.18 & 1.316 & 3.41 & 1.473 & 3.12 & 1.419 & 3.55 & 1.517 & 3.21 & 1.429 \\
\hline 10 & $\begin{array}{l}\text { Promo (Bonus } \\
\text { offer) }\end{array}$ & 3.75 & 1.600 & 3.39 & 1.446 & 3.78 & 1.616 & 3.78 & 1.616 & 4.16 & 1.830 & 3.79 & 1.690 & 3.87 & 1.661 & 3.93 & 1.692 \\
\hline \multicolumn{2}{|c|}{ AVG mean \& SD } & 3.82 & 1.672 & 3.53 & 1.549 & 3.79 & 1.633 & 3.70 & 1.582 & 4.00 & 1.716 & 3.74 & 1.626 & 3.63 & 1.588 & 3.69 & 1.613 \\
\hline \multicolumn{2}{|c|}{$\begin{array}{l}\text { Users' Perception with } \\
\text { Service quality }\end{array}$} & \multicolumn{4}{|c|}{ Low service quality } & \multicolumn{4}{|c|}{ High service quality } & \multicolumn{4}{|c|}{ Very Low service quality } & \multicolumn{4}{|c|}{ High service quality } \\
\hline
\end{tabular}

Looking at the table above, it is not surprising to find out using the average mean and above that the most perceived service gap by GSM users in Zaria metropolis is in mobile internet and Location Base Service where the entire networks users experienced gap with the services. From the analysis, etisalat network users perceived gap in only four (4) of the information services such as call, internet (data), Coverage map and LBS services hence provide high quality i.e good quality of six(6) information services. This was followed by airtel users that perceived gap in five (5) of the information services such as S.M.S, call services, Internet, Coverage map and LBS. On the other hand MTN users perceived gap in 
eight (8) of the information services received not up to expectation with the exception of S.M.S and caller tune that are of high quality. And GLO network users perceived gap in all the network services.

The finding is in accordance with that of Parasuraman, Ziethmel and berry (1986) where they observed that as service received up to or exceed expectation there is going to be high quality and high satisfaction, but as service received fall short of expectation as the case of MTN and, GLO services where gaps exist, quality decreases as well as satisfaction level. The gap could be attributed to the fact that services providers usually understand user's expectation from service providers' perception rather than from the users' perception.

\subsection{Objective 3: Level of Satisfaction of GSM Users with Information Services Quality provided by MCN in Zaria Metropolis}

Objective three attepmt to determine the level of users' satisfaction with information services provided by mobile networks in Zaria metropolis using likert scale of Highly satisfied, satisfied, no opinion, dissatisfied and highly dissatisfied considering the satisfied services those with average mean and above score to be the actual mean of acceptability in table below.

Table 3: Level of Users' Satisfaction with Networks Information Services in Zaria Metropolis

\begin{tabular}{|c|c|c|c|c|c|c|c|c|c|}
\hline \multirow[t]{3}{*}{$\mathbf{S} / \mathbf{n}$} & \multirow[t]{3}{*}{ Information Services } & \multicolumn{8}{|c|}{ Satisfaction Rating the quality of information services } \\
\hline & & \multicolumn{2}{|l|}{ MTN } & \multicolumn{2}{|l|}{ Airtel } & \multicolumn{2}{|l|}{ GLO } & \multicolumn{2}{|l|}{ Etisalat } \\
\hline & & MEAN & SD & MEAN & SD & MEAN & SD & MEAN & SD \\
\hline 1 & Call Services & 4.057 & 1.766 & 3.974 & 1.717 & 4.220 & 1.868 & 4.156 & 1.826 \\
\hline 2 & S.M.S & 4.134 & 1.813 & 4.011 & 1.739 & 4.234 & 1.877 & 4.161 & 1.829 \\
\hline 3 & M.M.S & 3.160 & 1.423 & 3.419 & 1.475 & 3.60 & 1.536 & 3.481 & 1.494 \\
\hline 4 & Mobile Internet & 3.757 & 1.603 & 3.854 & 1.652 & 3.989 & 1.726 & 4.112 & 1.799 \\
\hline 5 & Caller Ring Tone & 3.535 & 1.512 & 3.542 & 1.515 & 4.023 & 1.746 & 3.388 & 1.467 \\
\hline 6 & Coverage Map & 3.289 & 1.444 & 3.304 & 1.446 & 3.719 & 1.587 & 3.089 & 1.417 \\
\hline 7 & SIM Card Information & 3.941 & 1.699 & 4.157 & 1.827 & 4.306 & 1.925 & 4.026 & 1.747 \\
\hline 8 & Call Centre & 3.542 & 1.515 & 3.629 & 1.548 & 4.029 & 1.749 & 3.487 & 1.496 \\
\hline 9 & Location Base Services & 3.243 & 1.435 & 3.217 & 1.432 & 3.412 & 1.473 & 3.487 & 1.496 \\
\hline \multirow[t]{2}{*}{10} & Promo (Bonus offer) & 3.451 & 1.484 & 3.875 & 1.661 & 4.179 & 1.8941 & 3.917 & 1.686 \\
\hline & $\begin{array}{l}\text { AVERAGE MEAN AND } \\
\text { STANDARD 1DEVIATION }\end{array}$ & 3.611 & 1.570 & 3.69 & 1.60 & 3.97 & 1.861 & 3.73 & 1.630 \\
\hline
\end{tabular}

As indicated from research question four that users perceived the quality of information services high in some of the network services, likewise the satisfaction level of GSM users in all networks were satisfied with four of the services which are call, S.M.S, internet and SIM card. However they do not express their satisfaction with the M.M.S service. Analyzing the network services further, the table indicates that, apart from users expressing satisfaction in four services of all the network providers under study, GLO users expressed their satisfaction with seven of the services including caller ring tone, call center and promo.

Further attempt to analyzed the respondents base on satisfied quality service was carried out as all the network users expressed the satisfies quality service to be S.M.S services in four of the network providers as indicated with MTN network users that rated S.M.S service good and up to satisfaction level while the Airtel network users rated call, S.M.S, and promo as good and up to satisfaction level, then GLO network users rated none of the services as good but are satisfied with seven of the networks services and for Etisalat network, the users rated S.M.S, SIM card and promo as good and up to satisfaction level. The fact is that not all information services rated good or satisfied will be up high quality and high satisfaction level as the case of GLO were the users rated seven services as good but not up to satisfaction level as what Kano etall..(1996) observes in his model that identifies that high quality does not lead to high satisfaction for all services and vice versa.

However,looking at the previous researches conducted in Nigeria, no set of benchmark (standard) was used by network industries on information services to know the level of users' satisfaction. The researcher considered an existing bench mark by American customer satisfaction index (ACSI) of 95\% for communication services to enable the service providers to improve the quality and services satisfaction when compared. The researcher was able to come up with users' service satisfaction level of the entire network providers using likert scale which shows that not all the network services providers meet the ACSI bench mark of 95\% (completely satisfied). That is to say that not all network users are completely satisfied with the services but only partially satisfied of $75 \%$ as in the case of $\operatorname{GLO}(79.4 \%)$ and Etisalat $(75 \%)$ networks, while indicating below the average service satisfaction rating in MTN (72.2\%) and Airtel (74\%) networks. 


\section{SUMMARY OF THE FINDINGS}

Based on the analysis of the data collected, the following findings were summarized below

1. Call service, short message service (S.M.S),multimedia service (M.M.S), mobile internet, caller ring tone, coverage maps, SIM card information ,call centers, location base services(LBS) and promo(Bonus offer) werethe types information services provided by all the mobile network providers to GSM users in Zaria metropolis.

2. The study revealed that GSM users in all the mobile networks perceivedgap in mobile internet and LBS as they rated it as low quality. However, Etisalat networks usersperceived least gap in only four services as they rated six (6) of their services[S.M.S, M.M.S, Caller tune, SIM card information, call center, promo] to be good and of high quality in responding to users need. This was followed by Airtel with five (5) services[Call service, M.M.S, Caller ring tone, Coverage map, promo], then MTN with two (2) services [S.M.S, Caller ring tone] and GLO with none of it services rated as high and of good quality. This information service gapwas attributed to the understanding of users' expectation from the service providers' perception rather than from GSM users' perception.

3. The study revealed that GSM users were satisfied with four of the information services in all the network providers among which are the S.M.S that was rated good and highly satisfied, others are call service, internet and SIM card information, however only GLO network users express satisfaction that exceed the four services among which are caller ring tone, call center and promo

\subsection{Conclusion}

Considering the findings of this study, the study concludes that the mobile networks provide various information services to GSM users in Zaria metropolis to maintain and generate users. As Etisalat and Airtel network users experiences less gap with half of the information services rated good, the MTN and GLO network users experiences with the services is not up to expectation with less than $40 \%$ perceived services rating. However GLO network users were able to express their satisfaction with seven of their services, but were not able to rate the services as good quality. This has proved the Kano model that observed that not all services rated good are up to satisfaction level and vice versa.

Consequently it can be concluded that network users that experienced wide Gap with their information services given to them are likely to complain to their network providers. As GSM users complains with low quality and dissatisfied services it will be difficult for the network industries to get a big market share, protection from competitors, maintain and generate users, but as the GSM users are happy with the services of their network providers, the GSM users will be loyal to their network providers which in turns get a big market share in the telecommunication industries.

\subsection{Recommendations}

Base on the findings and conclusions, the following recommendations were raised:
1. There is need for mobile network to provide more information services (value added services) to get good market share, retain and generate users and to be able to protect themselves in the competing business of network industries globally.

2. Considering users experience with low service quality in this study as the case of MTN and GLO network. There is the need for mobile communication networks to consider adopting SERVQUAL model that is by using GSM users experienced with low service quality for this study especially in mobile internet and LBS to help in reducing information service gaps. The model emphasis on looking at the information services experience from the GSM users' perspective rather than from the network providers' perspectives.

3. Network providers'attention should be directed to services with lower satisfaction level like caller ring tone, Call center, promo with the exemption of GLO network, others are M.M.S, Coverage Map, LBS and the one that GSM users are likely to change their network providers with S.M.S by reducing the unwanted S.M.S to prevent them from losing customers. There should be a bench mark from the regulatory body (NCC) or by using an existing standard of ACSI to be used by service providers to enhance the satisfaction level of their users.

\section{REFERENCES}

[1] Adebisi, A. (2012). Customer Service Delivery and Subscribers Preference for Global System of Mobile Communication. Unpublished M.sc project: University of Ado- Ekiti, Ekiti State Nigeria.

[2] Babatunde, B. O., Ayaji, S. O. andOpaleye, M. A. (2012).Perception and Reaction of Subscribers to Service Cost of GSM Providers in Nigeria Telecommunication Section. School of Doctoral Studies (European Union) Journal, Osun state Nigeria, pp.223-229.

[3] Backlund, G. and Holmquist M. (2006).“Exceeding Customer Expectation an Online and Offline Perspective.

[4] Bettman, J., Luce, M and Payne, J. (1998). Constructive Consumer Choice Process, Journal of Consumer Research, 25(3), $187-217$.

[5] Collins, B. and Lara S. (2011) Telecommunication Regulatory Hand Book, International Telecommunication Union, U.S.A.

[6] Deoskar, A.A (2010). "A Study of Mobile Services from Customer Perspective", Department of Computer Management, University of Pune, India.

[7] Declaration on the Digital Devide(2012) "Transforming Drops of Concern into an Ocean of Change" download at: http://www.einclusionsite.org/eng/declaration eng.asp

[8] Dunnewijk, T. andHuten S. (2007). "A Brief History of Mobile Communication Network in Eu Espi (2006). Extended Performance Satisfaction Index (online) available http://www.epsirating.com/indexphp?optica.comrope" Telematic and Informatics 24(3): 164-179 
[9] Fornell, C. (1992). “A National Customer Satisfaction Barometer WLANS on Incumbent Cellular Service Providers in the U.S. A

[10] Gabriela, Baez et al. (2010). Impact of Mobile Service in Nigeria, Pyramid Research, NCC Abuja, Nigeria.

[11] Garvin, D.A. (1988). Managing Quality: The Strategic and Competitive Edge.The Free Press, New York, N.Y.

[12] Grot, J. and Dye R. (1999). Service Quality: Guidelines for Marketers. Managing Service quality, 9(5):337-358

[13] Gyan, C., et al (2006). A Survey of Customer Retention in the New Zealand Banking Industry: Bank and Bank system 1(4): 83-99.

[14] Hashed, A. N., Salniza S. and Hamid M. (2012) "Factors Affecting Customer Satisfaction of Mobile Services in Yemen, School of Business Management, University of Utara Malaysia. Available at http://journal.sapub.org.economic 2(7): 171-184.

[15] ITU (2003) "World Telecommunication Indicators". International Telecommunication Union Available online at http://www.itu./nt/-ITU-D/ICT/statitic.

[16] Jharwal, S.M (2005). Telecom Growth in India-New Initiatives, Employment News, p4-10 Kano, N. et al (1996). "Must -be Quality and Attractive Quality".The Best on Quality.\&:165

[17] Larry, G (2001) 100 years of Radio, Speech at WINLAB Marconi day commemoration, Red Bank, NJ

[18] Leadership (2013) Nigeria has over 113 million Subscribers available at http://leadership.ng/nga/article/47518/2013/ 02/12/nigeria-active-phone-subscribes-lines-ht113million. html

[19] Mohammad, A.etal..(2010) Customers Switching in Mobile Phone Providers in Pakistan International Journal of Bussiness Management.eco.res vol1(1)
[20] Omotayo, O. and Joachin A. (2008). Customer Services in the Retention of Mobile Phone Users in Nigeria, African Journal of Business Manager Vol. 2. Pp $026-$ 031.

[21] Ozer, G. and Aydin, S. (2005) National Customer Satisfaction Indices. An Implication in the Turkish Mobile Phone Market, Marketing Intelligence and Planning, 23(5), 486 - 504.

[22] Parasuraman, A., Zeithmal, A. \& Berry L. (1990). Delivery Quality Service: Balancing Customer Perception and Expectation, New York: The Free Press Division of Macmillan, Inc.

[23] Parasurama, A., Zeithmal, V.A. and Berry, L.L. (1986).SERUQUAL.A Multiple Item Scale for Measuring Consumer Perception of Service Quality, Journal of Retailing, 64(1), $12-40$.

[24] Pura, M. (2005). Linking Perceive Value and Loyalty in Location Base Mobile Services, Managing Service Quality, 15(6), 509-538.

[25] Souki, G.G. and Filho, C.G.(2008). Perceive Quality Satisfaction and Customer Loyalty: an Empirical Study in the Mobile Sector in Brazil. International Journal of Internet and Enterprise Management, 5(6) 298 - 312.

[26] Tung, L. L. (2004) Service Quality and Perceived Value's Impact on Satisfaction, Intension and Usage of Short Message Services (SMS).Information system frontiers 6 (4) 353- 368

[27] Taylor, A. and Baker, T.L. (1994).An Assessment of the Relationship between Service Quality and Customer Satisfaction in the Formation of Consumer Purchase Intention.Journal of Retailing, 70(2). $163-78$.

[28] Wood, R. (1997). Customer Value, the Next Sources of Competitive Advantage, J. Acad. Mark. Sci. 25(2): $139-$ 153. 